\title{
Paraplegic locomotion: a review
}

\author{
AV Nene ${ }^{1,2}$, HJ Hermens ${ }^{1}$ and G Zilvold ${ }^{2}$ \\ ${ }^{1}$ Roessingh Research and Development bv; ${ }^{2}$ Centrum voor Revalidatie Het Roessingh, The Netherlands
}

Keywords: spinal cord injury; paraplegia; locomotion; orthosis; functional electrical stimulation

\section{Introduction}

Paraplegia resulting from spinal cord injury (SCI) was known to physicians of ancient Egypt. ${ }^{1}$ However, very little concern was shown during that era regarding medium to long term management of paraplegic individuals because death usually occurred within a very short period. Even by the beginning of this century very little progress had been made. According to British military authorities' reports $95 \%$ of soldiers of the Balkan war who sustained SCI died within a few weeks of sustaining the injury. ${ }^{2}$ During the First World War almost $80 \%$ of all American soldiers who sustained SCI died before they could be returned home. ${ }^{3}$ Almost 20 years after the end of the First World War, Hinman ${ }^{4}$ reported that the commonest causes of deaths among patients with SCI were urinary tract infections and bed sores. Failure to prevent or control these complications accounted for over $80 \%$ of deaths. Only since the Second World War has the management of such patients improved, due to better methods of evacuation and transportation, advances in surgical techniques and the availability of antimicrobial therapy.

A catastrophe in one's life of such a magnitude as sudden transection or severe injury to the spinal cord inevitably has grave psycho-physical effects on one. The sudden conversion of a vigorously active person into a helpless physical entity leads to severe psychological shock. In this state of shock the paraplegic person is incapable of realizing the complete extent of his disability. This is followed by an early stage of shallow awareness of the disability. At first they are mainly concerned with the paralysis of their legs and questions such as 'Will I ever walk again? are common. However, as time progresses and the gravity of their situation sinks in, other problems, physical as well as those concerning activities of daily living, including walking becomes less important. Nevertheless, in lay person's eyes, inability to walk is the major disability a paraplegic person has and he/she experiences immense social pressures to attain an upright posture and walk again. Of late there has been an upsurge in the interest and new developments have occurred in the field of orthotics for paraplegic locomotion.

Correspondence: AV Nene, Roessingh Research \& Development bv, Roessingsbleekweg 33, 7522 AH Enschede, The Netherlands
During the last three decades rehabilitation engineers and clinicians have developed an interest in the field of Functional Electrical Stimulation (FES). The concept is based on a simple fact that the muscles with an intact reflex arc are electrically excitable and it was thought that this property could be used to provide all of the three basic requirements, ie stability, mobility and control, necessary for locomotion. However, the problems encountered during the application of this concept are still unsolved.

The intention of this review is to present the major scientific work concerning paraplegic locomotion reported in the literature. The number of studies is large and it is not possible to describe each study in detail. Some are described in detail while the others are mentioned in passing. The review begins with an overview of opinions regarding patient suitability. Work done on the physiological benefits of walking for paraplegic individuals is then briefly described, however, the studies concerning this aspect are somewhat limited. Before reviewing the varieties of walking systems fundamental components of locomotion are stated, then the varieties of orthoses used for paraplegic locomotion are briefly described. Within a framework of functionality, studies on energy requirements of paraplegic locomotion are discussed in somewhat greater detail, studies concerning other aspects of the functionality are then reviewed.

\section{Patient suitability}

In the course of rehabilitation of patients with SCI, therapists and physicians dealing with these patients need to know whether locomotion training should be carried out or not. Historically, physicians have held favorable views concerning benefits of upright posture and walking but their experiences have led to differences of opinion regarding advising patients with SCI in the usage of orthoses for locomotion. Clinicians, in the past, differed not only regarding which patients should be given orthoses, but also which factors should be taken into consideration when making this decision. Coonrad and Whiteside ${ }^{5}$ stressed that the patients' physical reserve, age and the nature of lesion, ie whether the lesion is partial or complete, should be taken into consideration. In their view paraplegic persons with a 
complete lesion above T10 were generally unsuitable for orthotic locomotion and they suggested that such patients should only be considered for wheelchair mobility. Hastings ${ }^{6}$ was of the opinion that a paraplegic individual with a complete lesion above T12 should not ambulate with crutches and braces, whereas Zankel and associates ${ }^{7}$ found no correlation between level of injury and ability to ambulate. They concluded that the severity of injury, rather than level, was the major determinant of a patient's ability to walk. Munro $^{8,9}$ believed that any patient with strong arms and equally strong motivation could ambulate. Long and Lawton ${ }^{10}$ defined physical activity goals for patients with SCI and related these goals to the level of injury. However, they also asked to take into consideration other factors which might influence the patient's ability to ambulate such as spasticity, decubitus ulcers, urinary tract infections and motivation. In that study they suggested that, (a) only exceptional patients with levels of injury above T12 could achieve any form of functional locomotion, and (b) independent locomotion, even with the help of equipment, could only be achieved by patients with injury levels below L4. Gordon and Vanderwalde ${ }^{11}$ cited many factors which contribute to difficulty in locomotion in paraplegic people namely age, weight, motivation, inherent agility and co-ordination, economy of motion and the degree of spasticity.

There have also been considerable differences in opinions regarding the extent of bracing required for paraplegic locomotion. Covalt and associates ${ }^{12}$ stated that patients with lesion levels above T10 should be fitted with Knee Ankle Foot Orthoses (KAFOs) along with a pelvic band with a Knight spinal attachment. Patients with lesions below T10 should have only a pelvic band with KAFOs and patients with low lumbar or incomplete lesions should have KAFOs only. Abramson ${ }^{13}$ firmly believed that pelvic bands and back braces attached to KAFOs are rarely, if ever, necessary. He expressed a view that use of a wheelchair as the sole means of mobility had definite drawbacks and advocated a combination of crutch and brace walking and wheelchair mobility as the most acceptable and practical approach in a majority of patients with SCI.

In the past only two groups of patients have most frequently been considered suitable candidates for locomotion, namely (a) patients with injury at the Thoraco-Lumbar level and (b) patients with an incomplete injury. Taking into consideration a marked variation in the neurological recovery following an incomplete injury, and the presence of a large number of spinal cord segments at the ThoracoLumbar level, it is very difficult to predict with any accuracy the locomotor outcome of these patients at an early stage of rehabilitation. Hussey and Stauffer ${ }^{14}$ reviewed all patients admitted to Rancho Los Amigos Hospital SCI service with incomplete SCI and complete paraplegic patients with Thoracic or lower level injuries. Out of 782 patients admitted during the period of the study 176 had attained some degree of ambulatory function during their rehabilitation period in the hospital. From this group only 164 patients were included in the review because the remaining 12 did not have complete data subsequent to their discharge from the hospital and hence were excluded from the study. Ambulation was graded in four categories namely: community, household, exercise and nonambulatory. Community ambulators were defined as those who were able to get themselves out of a wheelchair or bed and walk for reasonable distances both in and out of the house unassisted. They may use braces and/or crutches and may use a wheelchair for long distances. Household ambulators were those who required assistance in getting out of bed or wheelchair, were able to walk within the house with relative independence, but were unable to ambulate outside for any significant distance and used a wheelchair. Exercise ambulators required significant assistance in order to ambulate. Nonambulators only used a wheelchair. Both, the community and the household ambulators were considered to be functional ambulators. At the time of the study, out of the 164 patients studied, 82 were community walkers, 13 were household walkers, 25 were exercise walkers and 44 were non walkers. The authors concluded that no patient achieved any form of functional ambulation without pelvic control. Hip flexors also appeared to be essential. Hip abductors and extensors seemed less essential; crutches compensated for these deficits adequately. The quadricep muscles appeared to be important for functional ambulation particularly with regard to community ambulation. Knee flexors and ankle-foot musculature seemed to be less important in determining the patient's level of ambulation. Sensation, in particular proprioception appeared to be important in allowing functional ambulation. Age, deformity and spasticity were three factors which when superimposed on the neurological deficits diminished the functional level achieved by the patient. Rossman and Spira ${ }^{15}$ and Stauffer and associates ${ }^{16}$ in separate studies also found that patients with paralysis at the level of T12 and above could not become functional ambulators and did not use their braces regularly.

It appears that there are many physical factors which determine whether a paraplegic individual can achieve functional ambulation or not, the most important being the anatomical level of the lesion. Other physical factors include spasticity, weight, spinal and limb deformities, co-ordination, intelligence, renal abnormalities and decubitis. Advancing age and the presence of the above-mentioned adverse physical factors seem to reduce the ability of a paraplegic person to ambulate. Another most important factor is the provision of adequate bracing. Past experiences with the paraplegic locomotion were confined to provision of bilateral KAFOs either with or without a pelvic band and in some cases providing additional spinal orthosis. Rose ${ }^{17}$ was first to think of combining the spinal support and the leg calipers. He scientifically 
studied various ways of guiding the hip joint paths and suggested an orthotic system then known as the Hip Guidance Orthosis (HGO). This was at first used for children with congenital paraplegia resulting from myelomeningocele. Since 1981 the system has been used for adult traumatic paraplegics. Douglas and associates ${ }^{18}$ reported another concept of guiding hip joint paths via Bowden cables. This orthotic system became known as the Louisiana State University Reciprocating Gait Orthosis (LSU-RGO). Both these orthoses incorporate truncal support and are of HipKnee-Ankle-Foot variety (HKAFO). They enable paraplegic patients with a thoracic level lesion to ambulate. This is in contradiction to the views held by clinicians in the past. However, detailed analysis, both physiological and mechanical, of these systems is only recently emerging. It appears that with adequate bracing paraplegic people with thoracic level lesions can ambulate at an equivalent or in some instances lower energy requirements than those with lower lesions ambulating with bilateral KAFOs. Those with lumbar level lesions or with an incomplete motor lesion are more suitable for ambulation with KAFOs and those with lesions at the cauda equina level or above require HKAFOs.

\section{Physiological benefits of walking}

Besides claims made by many patients of the benefits from the psychological point of view many authors have believed that real physiological benefits are obtained from movement in general and walking in particular. The alleged benefits are:

(a) Prevention of osteoporosis and thereby reducing the incidence of fractures

(b) Reduced incidence of urinary calcinosis

(c) Reduction in spasticity

(d) Aiding digestion

(e) Prevention of decubitus ulcers

(f) Reduced heterotopic ossification $3,12,13,19-25$

Guttmann $^{26}$ stated that as soon as the paraplegic patient is up in his wheelchair, intensive physiotherapy including standing and in particular sporting activities are invaluable in combating osteoporosis. Rosenstein and associate ${ }^{27}$ studied the effects of various factors and in particular of ambulatory status on bone density of myelomeningocele patients with lesion levels in the thoracic and lumbar regions. They found that in the upper extremities the bone density primarily was low in thoracic level patients but in the tibia and metatarsal it showed a more linear correlation with neurological levels. They concluded that although the ambulatory status (weight bearing stresses) and the neurological status (muscle stresses) are both important factors in maintaining bone density, the latter is a more important determinant. Mazur and associates ${ }^{28}$ determined the benefits of walking at an early age in patients with high level spina bifida by comparing two matched groups of patients. The first group consisted of patients who were encouraged to walk from an early age and participated in a walking program and the second group consisted of patients who were wheelchair users. They found that patients who walked early had fewer fractures and pressure sores. They were more independent and were better able to transfer than were patients who had used a wheelchair from an early age.

Messenger and associates ${ }^{29}$ studied the effects of ambulation on the blood flow in the lower extremities of paraplegic patients (Myelomeningocele and Posttrauma) using a non invasive transcutaneous blood gas monitoring technique. A similar study was carried out in normal control subjects. The electrodes monitoring transcutaneous blood gas partial pressure of oxygen $\left(\mathrm{tPo}_{2}\right)$ and carbon dioxide $\left(\mathrm{tPcO}_{2}\right)$ were positioned on the chests and legs of subjects of both groups. The measurements were carried out for both groups when the subjects were resting in a sitting position and when standing following ambulation. There was no significant difference in the transcutaneous blood gas partial pressures of $\mathrm{O}_{2}$ and $\mathrm{CO}_{2}$ thereby indicating no difference in the circulation of paraplegic people when either standing or sitting.

More recently Ogilvie and associates ${ }^{30}$ studied a group of paraplegic patients using an ambulatory orthosis for the first time since their injury, thus, changing their wholly sedentary life style to one which included regular periods of weight bearing upright posture and walking. They noted very little apparent benefit in respiratory mechanics. There was a subjective reduction in urinary tract infections but without a corresponding reduction in the level of bacteria. A small improvement in bone density was noted in a small subgroup. They concluded that at least in the shorter term (study period 18-30 months) the physiological benefits of using a walking orthosis for a paraplegic person were not as great as had been generally claimed in the literature.

The majority of publications reporting the physiological effects of ambulatory status are related to myelomeningocele patients. Only recently a few reports of the findings in adult paraplegic patients have appeared in literature.

\section{Varieties of orthoses}

Stallard and associates ${ }^{31}$ reviewed fundamental design problems of providing ambulation for paraplegic patients. They were of the opinion that there are fundamental requirements which any walking system must satisfy and during consideration of any orthotic options their efficiency in providing these requirements must be assessed. They also felt that the developers of an orthotic system may make compromises in one or more areas of design with a trade-off in the other areas. The prescriber must be aware of both, the fundamental requirements and the compromises made by the developers of the system under consideration. It would be appropriate at this point to review, very briefly, the fundamental components of orthotic locomotion. 
Swivel walker

The Swivel Walker was established as a means of ambulation for severely disabled children by Motlock and Elliott ${ }^{34}$ as early as 1966. Edbrooke ${ }^{35}$ described another design. Rose and Henshaw ${ }^{36,37}$ described an updated version of the design described by Edbrooke. Experience of its usage for adult paraplegic ambulation has been described by Farmer and associates ${ }^{38}$ and engineering design considerations have been detailed by Stallard and associates. ${ }^{39}$

A Swivel Walker enables paraplegic patients with lesion levels below C6 to ambulate in an upright position without the use of any other walking aids. It consists of a rigid body structure which provides intrinsic stability via a frame with three point fixation of hips, knees and ankles. The extrinsic stability is provided by a pair of swivelling foot-plates mounted beneath the body frame. In addition to providing extrinsic stability they also provide a means of mobility. The center of mass of the system is arranged to fall slightly forwards of the foot-plate bearing center; so when inclined to one side it tends to cause forward movement. Ambulation is achieved by alternately sideways rocking of the trunk so that one foot-plate is lifted clear off the ground, the frame then automatically swivels forward on the grounded footplate. Rocking to the other side lifts clear the previously grounded footplate and then the frame again automatically swivels forward on the now grounded footplate. The process continues in a repetitive fashion. More active patients swing their arms in opposite direction to that of the frame increasing the rotation effect. The orthosis is available in a modular form. The main components alter in size according to the patient requirements.

Although the swivel walker, in some cases, provides independence in getting in and out of it for a paraplegic person, the final stage of transfer of attaining an upright position needs to be carried out by helpers. The ambulation achieved by the patients is slow and is restricted to an even level surface only. in the patient who is being supplied with orthosis. In those with complete paraplegia almost all of these basic requirements are absent and an orthosis is supposed to provide at least one or more of these requirements.

Presently there are three approaches which can be considered in the provision of orthosis for a paraplegic patient for ambulation.

(1) Mechanical Orthosis

(2) Functional Electrical Stimulation (FES) and

(3) Hybrid Orthosis-Combination of a mechanical orthosis and FES

\section{Mechanical orthoses}

A variety of mechanical orthoses have been used in the past and they continue to be used. They vary from a Swivel Walker, which is almost like a standing frame with a limited facility to move from place to place, to Ankle-Foot Orthosis (AFO).
ParaWalker (Hip Guidance Orthosis, HGO) (Figure 1) Following a thorough analysis of requirements of reciprocal walking for paraplegic patients Rose $^{17}$ tried and tested a system of orthosis consisting of specially designed hip guidance articulations. The orthosis was initially called the Hip Guidance Orthosis but lately when it became routinely available for adult paraplegics it became known as the ParaWalker. The orthosis has a rigid body brace with two KAFOs attached to it via the specially designed hip joints. The KAFOs are in minimal abduction at the hips in relation to the trunk. The orthosis has three support points. A support point on the chest is provided by a leather chest strap. A support point on the buttocks is provided by a polypropylene band attached on either side directly to the hip joint housing. It has relatively low friction hip joints with flexion/extension stops. A 


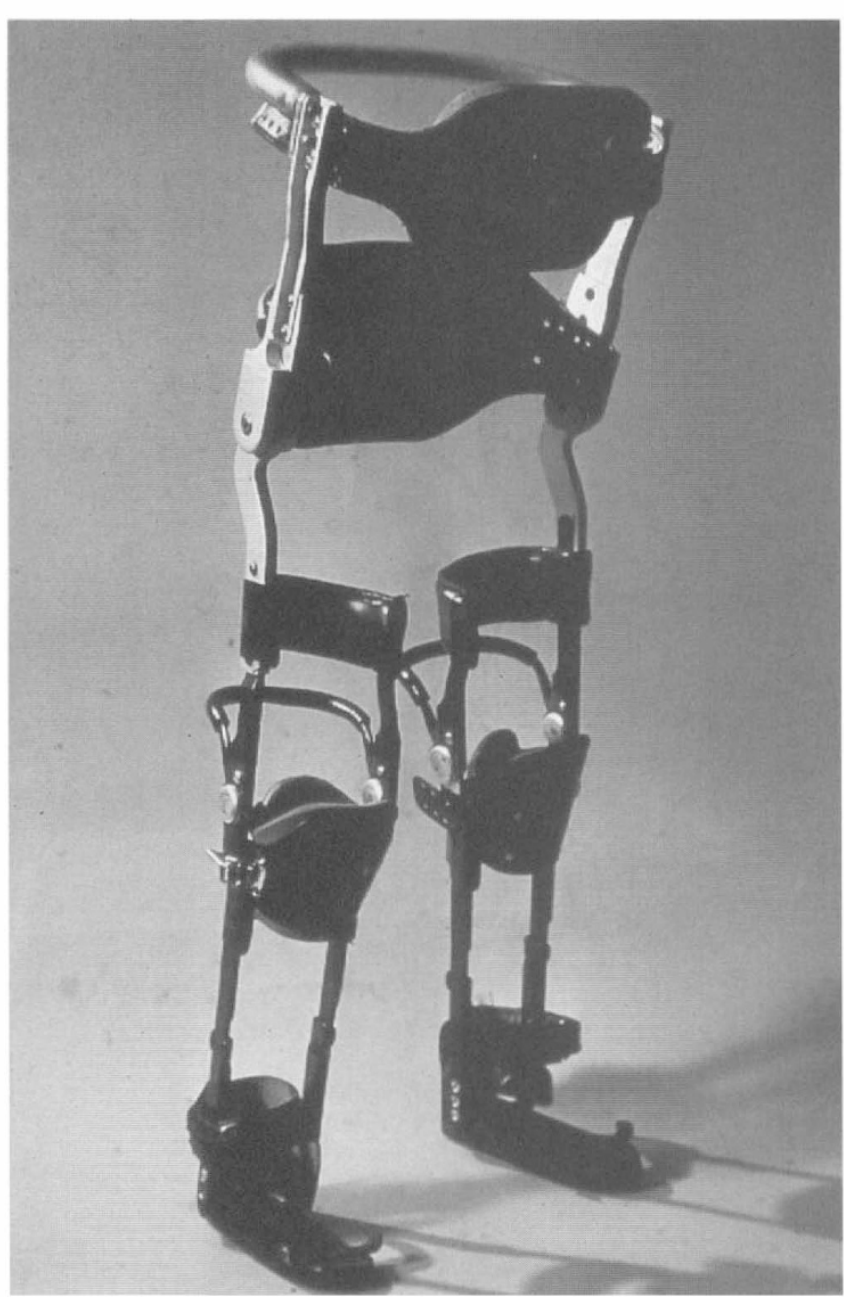

Figure 1 ParaWalker

release mechanism for the stops is provided to allow the user to sit down. The KAFOs stabilize knees and ankles. The knee on either side is held in extension by an anterior strap at the level of upper end of the tibia reacted by the posterior thigh band and a vertical extension on the rear of the shoe plate. These together provide the third support point for the main orthosis. The orthotic knee joints are normally locked during ambulation but have release mechanisms to enable the user to sit down. A shoe plate incorporating a rocker sole is fixed to either KAFO with an appropriate amount of dorsiflexion. There are simple fasteners to ease doffing and donning of the orthosis.

The system allows reciprocal walking for thoracic level paraplegic patients. Butler and associates ${ }^{40}$ studied the technique of reciprocal walking using the ParaWalker with crutches. The rigid body brace of the ParaWalker can resist the adducting movements about the stance hip in the coronal plane. A push on the crutch to tilt towards the stance side allows the patient to clear the swing leg. As soon as the swing leg is clear off the ground gravity causes it to move forward through pendulum action causing flexion at the hip. This is possible because the center of mass of the leg lies behind the hip joint axis when it is in extension. The flexion is limited by stops on the hip joint. When the swinging leg contacts the ground it is in flexion. Injection of force is required to raise the trunk upwards and pull it forwards during stance. This force is provided by the patient, through the same crutch which tilts him sideways, using the Latissimus dorsi muscles to pull the trunk towards the arm.

Reciprocating Gait Orthosis (RGO) (Figures 2a and b) The principle of linking hips together to allow reciprocal movement of both hips in HKAFO was first developed in late 1960's. At the Ontario Crippled Children's Center in Toronto, Canada Motloch and his colleagues described a mechanism based on the use of gears. ${ }^{41}$ In England, David Scrutton ${ }^{42}$ described the use of a pair of Bowden cables to control motion of orthotic hip joints in a reciprocating brace with polyplanar hip hinges used for spina bifida children.

The reciprocating gait orthosis, which is a refinement on the original design described by Scrutton, was jointly developed by the Louisiana State University Medical Center and Durr-Fillauer Medical Inc and has been in use for several years. ${ }^{18}$ The orthosis includes trunk support, a pelvic assembly and bilateral KAFOs. The thoracic support consists of extensions of upper side members of hips up to or just above the level of the xiphoid process of the sternum with 2 inch wide adjustable anterior and posterior encircling straps. The extension prevents uncontrolled collapse of the trunk and yet allows the user to move upper extremities freely. The rigid pelvic assembly consists of a pelvic band covering the gluteal and sacral areas with special thrust bearing hip joints coupled together with a cable and conduit. The KAFOs have posterior offset knee joints with drop locks on lateral sides. The AFOs and thigh sections are made of Polypropylene. The AFOs are each reinforced in the ankle area with an insert made of a composite material to assure resistance against dorsiflexion. The most important feature of the system is the cable coupling to each extremity. The coupling provides hip joint stability during standing by preventing simultaneous flexion of both hips; yet it allows flexion of one hip and simultaneous extension of the other when a step is taken. The cables can be disengaged to sit down.

Solomonow and his associates ${ }^{43}$ described several limitations of the original orthotic system which were encountered during it's usage and suggested modifications to the system. In their experience most patients were able to doff and don the orthosis independently but were unable to stand up without assistance. Many paraplegic patients have some degree of Hamstring contracture and hence their knees cannot reach full extension. Since the automatic knee locks operated only in full extension these patients were unable to 


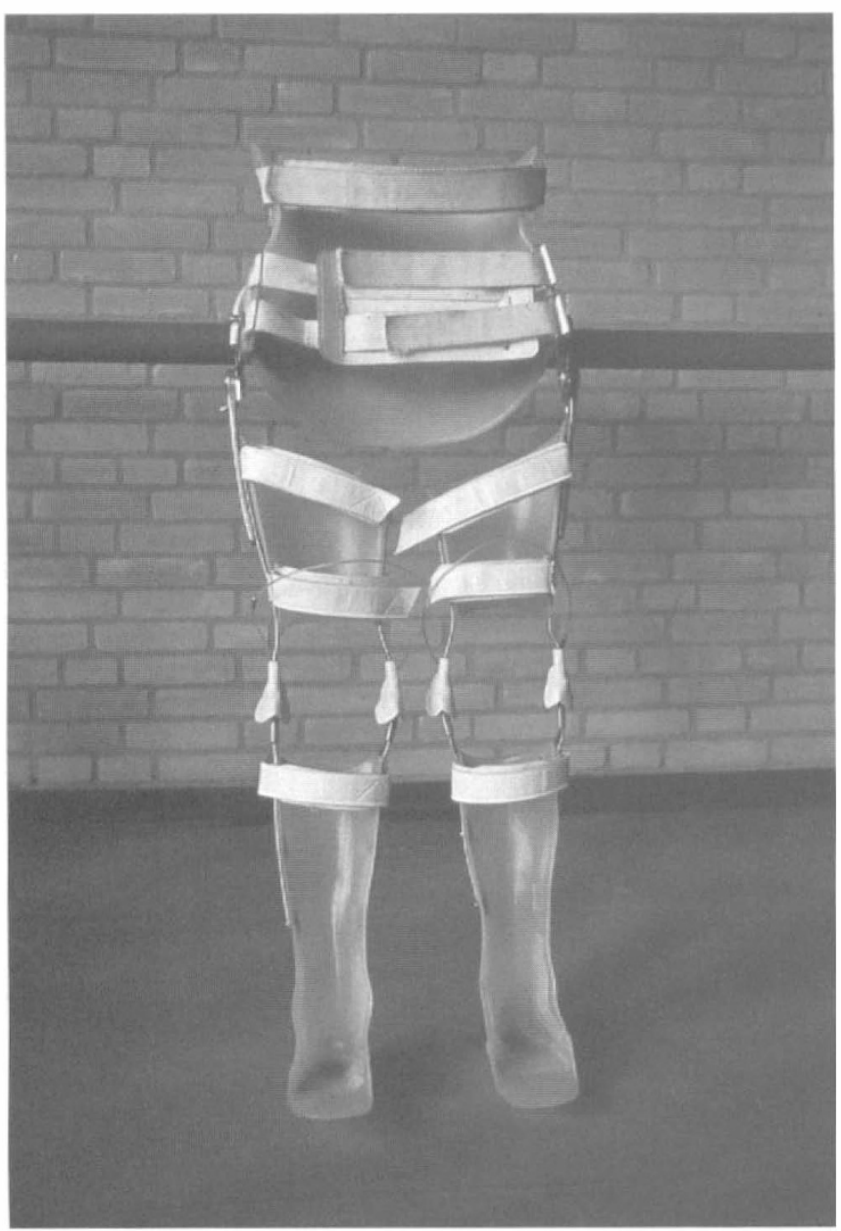

b

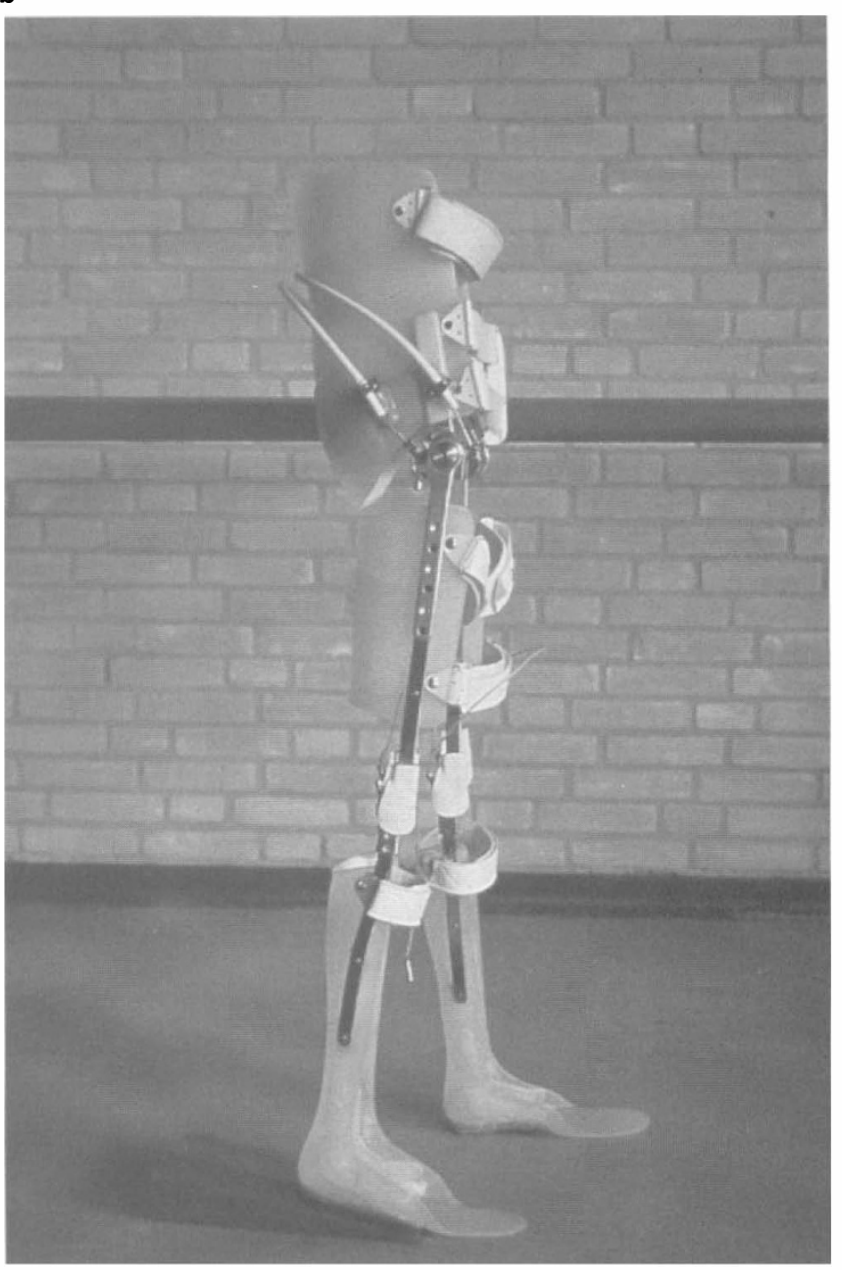

Figure 2 Reciprocating gait orthosis (RGO) (a) Frontal view (b) Side view

remain upright. Another major concern was the inability to negotiate ramps or driveways with mild to moderate inclines.

A ratchet knee joint was incorporated into the design. This knee joint extends freely but locks in any position short of full extension. This prevents the knee from flexing during the process of standing up even if it is not fully extended and supports the patient's weight. Force applied to the knee at heel strike of the first step brings it into full extension. The ratchet knee joint has a bale type lock which can be operated to allow free flexion to enable the patient to sit down.

A new hip joint has been designed. This has two locking positions. First is the standard position at full hip extension to attain normal upright posture. The second position allows $20^{\circ}$ flexion from the first position. This allows the patient to move the center of mass of upper trunk forward, so that while walking on the ramp it would remain in front of the support area preventing loss of balance posteriorly.

Whittle ${ }^{44}$ studied orthotic gaits of patients using the RGO and the ParaWalker as a part of comparative biomechanical assessment of these two orthoses. He found similar walking velocities for both orthoses. The total excursion of the leg in the sagittal plane (flexion/ extension) was significantly greater with the RGO. However, the stride length was similar for both orthoses, because, in the ParaWalker gait the smaller leg excursion was compensated by greater pelvic rotation in the transverse plane. Also, during the ParaWalker gait there was significantly greater abduction of hip on the swing side and smaller adduction of hip on the stance side, making it easier to use with crutches. The patients were unable to use crutches with the RGO. The force through the legs was a little higher with the ParaWalker. The force through the arms was probably higher with the RGO.

\section{Advanced Reciprocating Gait Orthosis (ARGO) \\ (Figures $3 a$ and $b$ )}

Although the crossed Bowden cables are a simple and effective way to produce reciprocal hip joint motion they may not be the most efficient mechanical coupling. 


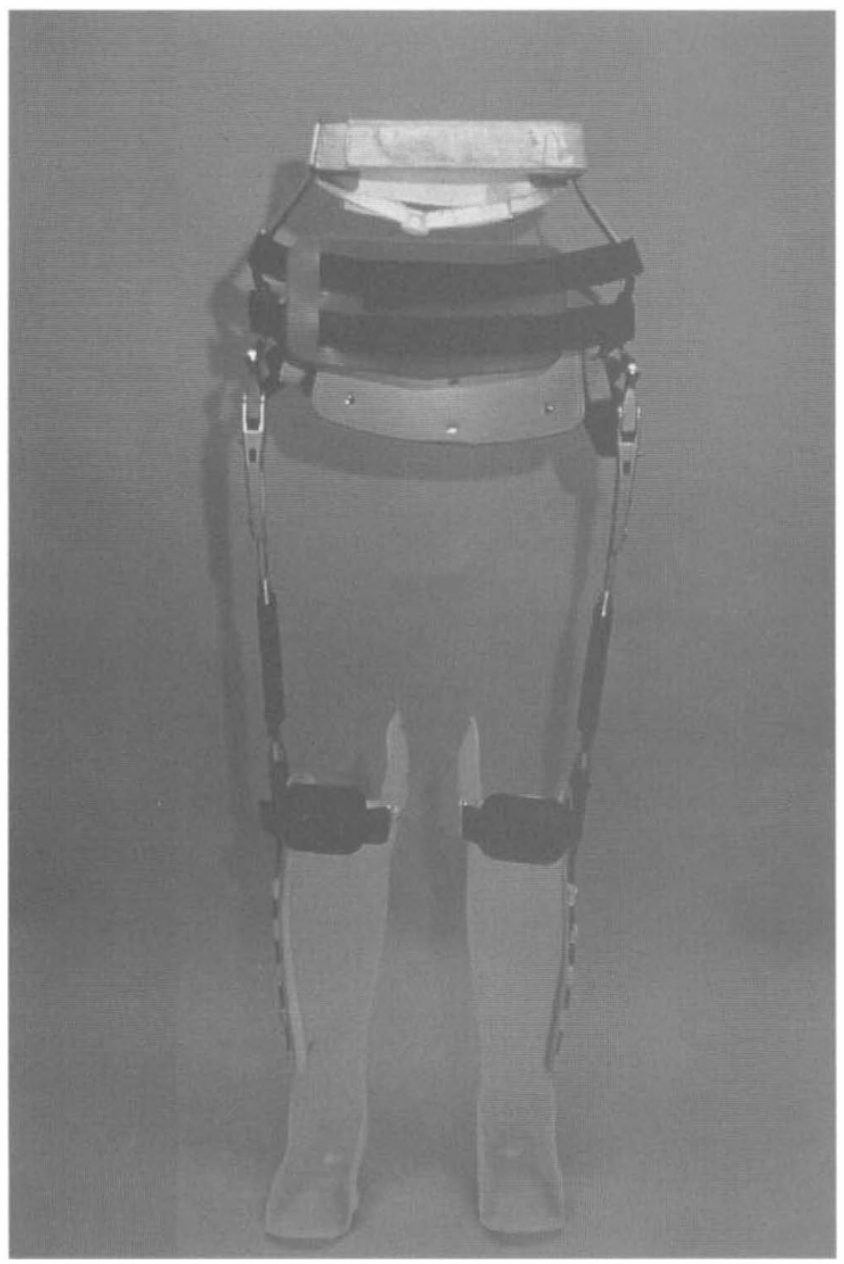

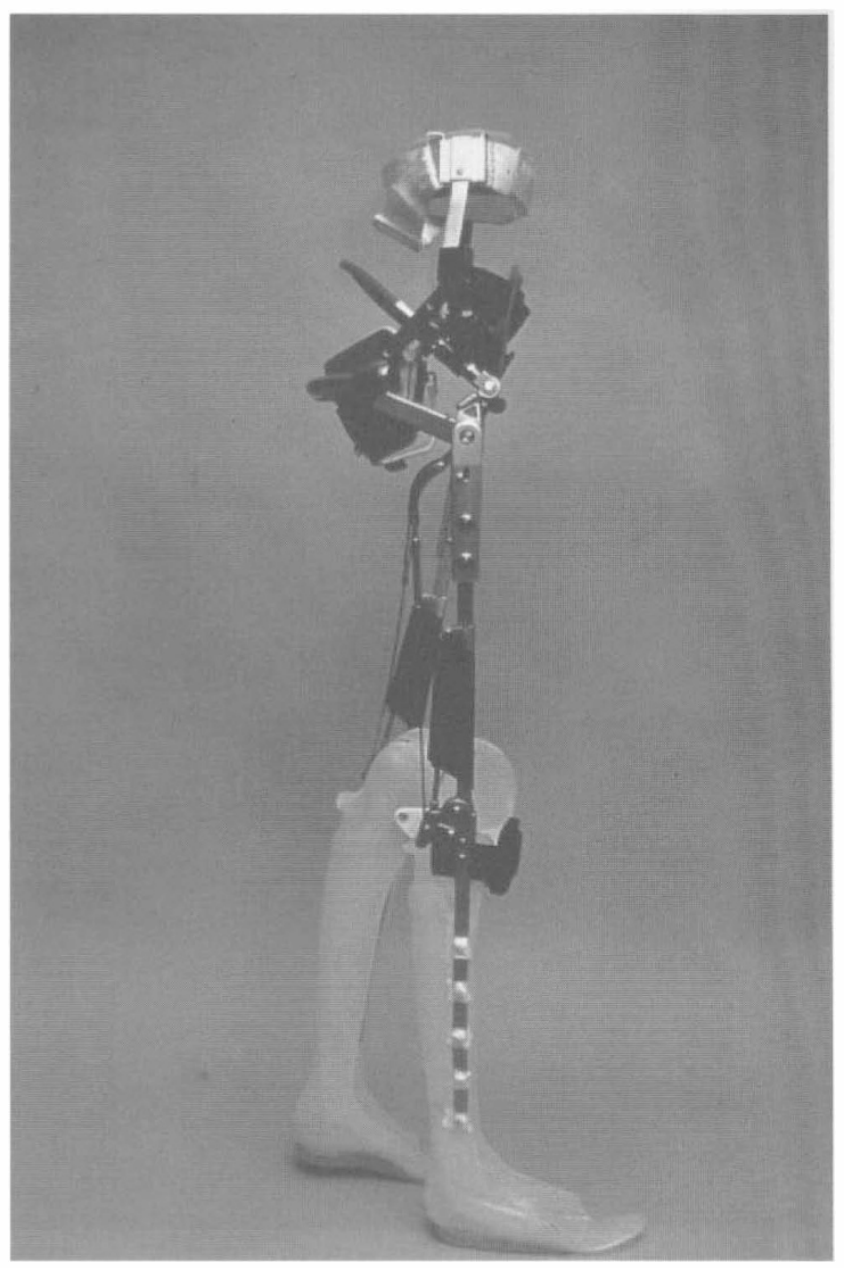

Figure 3 Advanced reciprocating gait orthosis (ARGO) (a) Frontal view (b) Side view

Since the cables are secured only at each end some of the energy associated with active hip extension is wasted in unwanted cable friction. Also, since a cable needs to be in tension to transmit large forces effectively only half of the system is being used at a time. A modified version of RGO called Advanced Reciprocating Gait Orthosis (ARGO) has been described (Hugh Steeper Ltd). The hip joints are modified and are interconnected using a single Bowden cable encased in a tube in an attempt to reduce friction. Its major advantage over the $\mathrm{RGO}$ is that it allows the user to rise from sitting position and to sit down from standing position with relative ease. The user can stand up directly from normal sitting position with flexed knees without having to extend them manually before commencing to stand up as is necessary with RGO as well as the ParaWalker. This is achieved by mounting a compressed gas strut on the thigh side member on each side providing a knee extension movement to augment standing and control hip flexion during sitting down. The hip and knee joints on each side are connected via a knee lock actuating cable so that the hip mechanism releases the knee lock.
Jefferson and Whittle ${ }^{45}$ during development of the ARGO, studied a subject using the ParaWalker, RGO and the ARGO. They found similar motion, in pattern and in magnitude, with the RGO and ARGO. However in the ARGO the pelvis appeared to be momentarily stationary at a particular instant during the gait cycle enhancing it's jerky movement pattern. The ParaWalker walking showed marked differences from that of the other two. It showed greater smoothness of the fore and aft movements. The subject's legs remained more or less parallel to each other in the coronal plane allowing better ground clearance.

Motlock $^{46}$ suggested another modification to the RGO known as the Isocentric RGO. He suggested replacement of the crossed bowden cables, which couple hip extension to contralateral hip flexion, with a centrally pivoting bar and tie rod arrangement (Figure 4). Winchester and associates ${ }^{47}$ tried out the effects of this arrangement on the walking performances of four paraplegic patients. The results of this study are reviewed in a later section. 


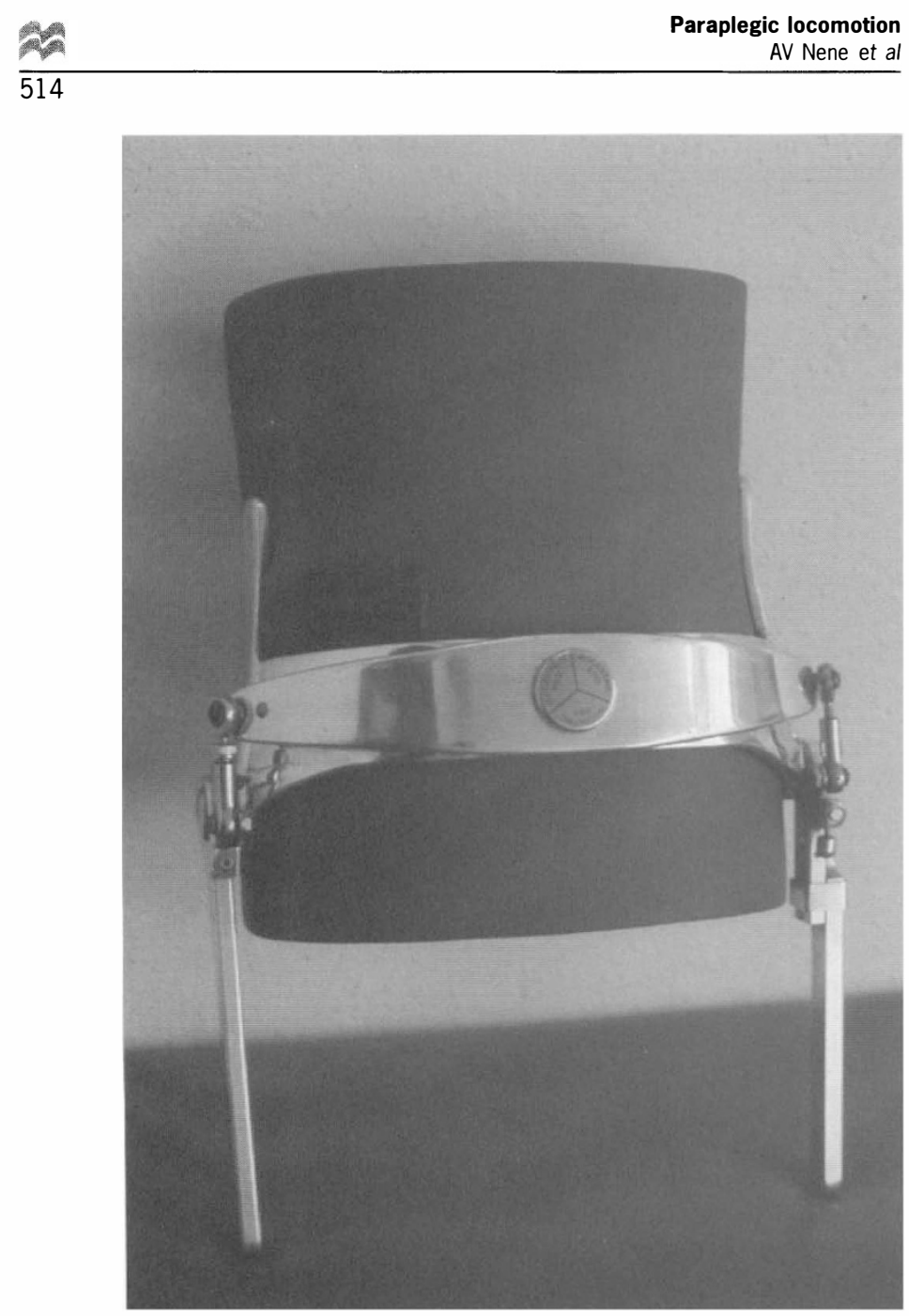

Figure 4 Pivoting tie rod arrangement of Isocentric ${ }^{\mathrm{R}}$ RGO (Illustration by courtesy of the Centre for Orthotics Design Inc, 1629 Main Street, Redwood City, CA 94063. Isocentric ${ }^{\circledR}$ is a registered trademark of the Centre for Orthotics Design Inc.)

Knee-Ankle-Foot-Orthosis (KAFO) (Figure 5)

Knee-Ankle-Foot-Orthosis, as the name suggests, provides stabilization of the knee along with stabilization of the ankle and foot. This is achieved by application of three forces. The first is applied in front of the knee preventing it from buckling under the body weight and the other two forces are applied in an opposite direction to that of the first, ie posteriorly, one at the upper posterior thigh and the other at shoe level.

In the past KAFOs were extensions of below knee double iron orthosis. Traditionally they were attached at the lower end to a firm lace up shoe through a stirrup or a round caliper. The ankle joint provided medio-lateral stability; it was similar to traditional $\mathrm{AFO}$, in that, it had a posterior stop to prevent plantarflexion but allowed dorsiflexion. A knee joint, with or without lock, was added at the level of the knee. Most KAFOs used for paraplegic locomotion

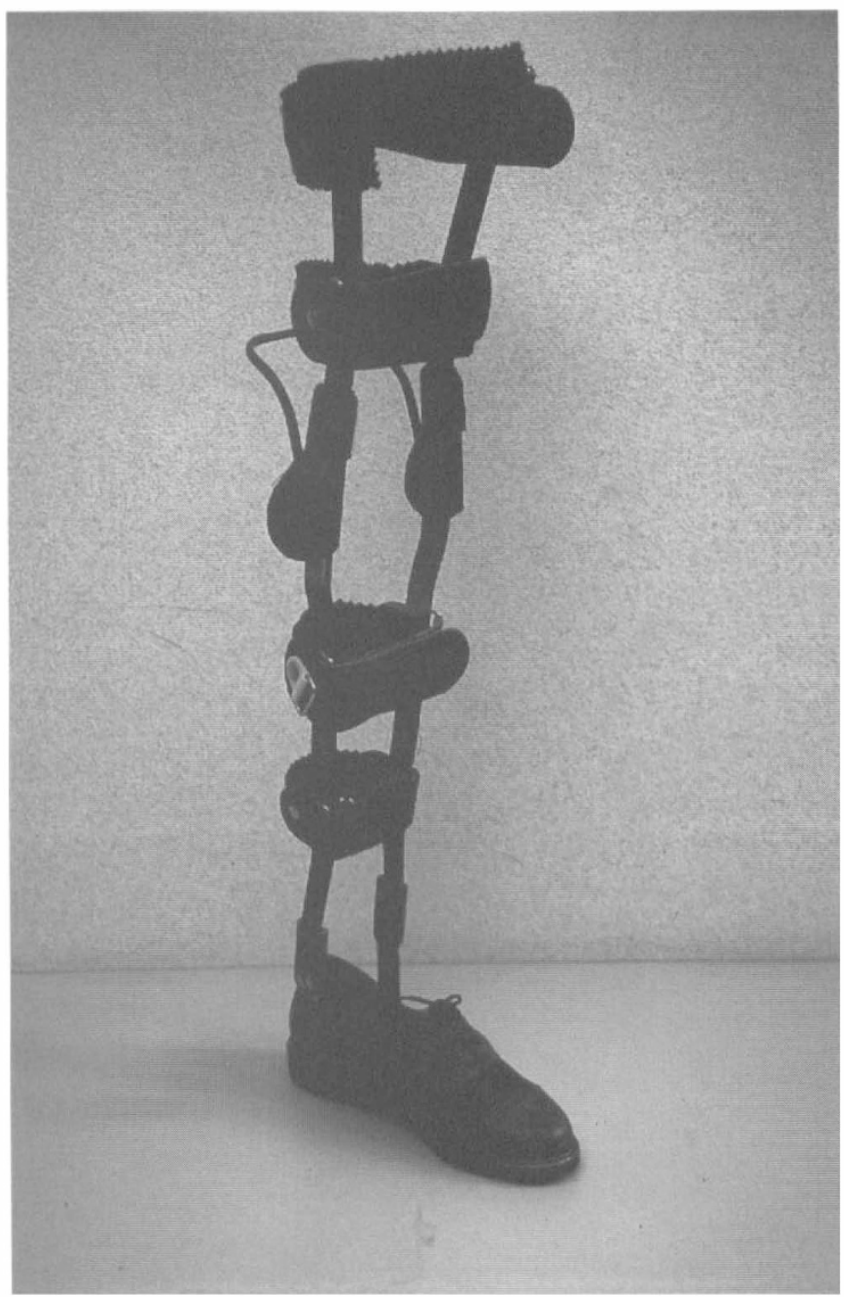

Figure 5 A Knee-Ankle-Foot-Orthosis (KAFO)

have knees with locks so that they are locked during standing or walking but could be unlocked during sitting. The simplest lock is a drop lock which is unlocked after sitting down. A bale or swiss lock provided easier locking and unlocking mechanism. The most essential bands on a KAFO are posterior calf and upper thigh bands. A large variety of other combinations of thigh and calf bands have been described. However, Lehmann and associates ${ }^{48-50}$ showed that most of these additional bands are often unnecessary. Some KAFOs are fitted with pelvic bands in order to help stabilize the pelvic girdle. Theoretically these orthoses are Hip-Knee-Ankle-Foot variety (HKAFO) and should not be classed as KAFOs.

The Scott-Craig Orthosis was originally designed by Bruce A Scott and Pat Rogge and then was further developed by Alton A Scott and HR Hahn at Craig Rehabilitation Hospital, Englewood, Colorado, USA. $^{50}$ Bruce A Scott ${ }^{51}$ described several modifications of traditional KAFOs with the intention of 
making them lighter in weight and giving a more stable base with improved balance to the user. Supporting bands were discarded except for a rigid posterior thigh band with soft front closure and an anterior rigid tibial band which is solid, heavily padded, hinged and fitted with a snap lock for donning and doffing. The knee was offset eccentrically. Bale locks were retained. The shoe plate was extended beyond the metatarsal heads. A solid ankle was set in $5-10^{\circ}$ dorsiflexion and was reinforced with lateral supports from the stirrups to sole plates. This $\mathrm{KAFO}$ is now the one which is the most commonly prescribed type of orthosis for paraplegic patients.

Ambulating with knees locked in full extension in a swing-through or a swing-to fashion requires lifting the center of mass up at every step. This increases the energy cost of ambulation, however, this is accepted as a trade off with the increased amount of safety due to locked stable knees. Locked knees allow the patient to lean backward to stabilize the hips. Leaning backward, with locked knees, places the center of mass of the trunk behind the hip joint resulting in tightening of anterior hip capsule providing internal stabilization of the hip.

\section{Ankle-Foot-Orthosis ( $A F O$ )}

Only one orthotic system of this variety has been described for ambulatory use for paraplegic patients. ${ }^{52}$ The Vannini-Rizzoli Stabilizing Limb Orthosis (VRLSO) comprises of a pair of polypropylene orthosis shaped to fit the lower legs. An orthosis on each side partially encloses the lower leg from about $2 \mathrm{~cm}$ below the lower pole of patella to tips of the toes. A pair of specially designed leather boots fit over the orthosis. The $\mathrm{V}$-RLSO has a flat rigid sole externally and the inside of the orthosis is $10-15^{\circ}$ plantarflexed in order to shift the ground reaction in front of the ankle and knee during standing. Three varieties of boots are available for use with the orthosis. For winter use the boot is made of leather reaching up to just below the tibial tuberosity. There are two zip fasteners on either side and a central lace. The lace needs to be adjusted only initially, the zips are then used to doff and don the boot. Boots are padded internally for skin protection. For summer use there is an anteriorly open version equipped with velcro fasteners and is intended for indoor use. A shortened version of the winter model is also available.

When using this system the patient controls static equilibrium by maintaining hips and knees in extended position and head held high. During ambulation, by shifting the upper torso slightly towards the side and forward the patient can shift the center of mass forward and then with the help of walking aids is able to move the unweighted foot forward in a pendulum fashion.

\section{Functional Electrical Stimulation (FES)}

Development of electronics and increased knowledge of the electrical excitability of nerves made it possible for Liberson and associates ${ }^{53}$ to design an electrical stimulator which was used to prevent foot-drop in hemiplegic patients. This opened up a new field of rehabilitation technology involving physicians and engineers working together. FES has been described as electrical stimulation of muscles deprived of nervous control with a view to providing muscular contraction and produce a functionally useful movement. Extensive research work has been carried out in the use of FES for the lower extremities to enable paraplegic individuals to stand and ambulate. There were sporadic reports of FES usage in patients during early years but concerted efforts to restore function in paraplegic patients by means of electrical stimulation were started by Kralj and his associates. $^{54,55}$ The first report of the use of FES to achieve walking for a complete paraplegic patient appeared in $1980 .{ }^{56}$ Use of the preserved withdrawal reflex to achieve swing of the leg along with stimulation of the contralateral Quadriceps to provide stance stability was suggested in that report. A simple four channel surface stimulator with totally open loop control was introduced in clinical practice. $^{57,58}$ This has been the simplest and the most commonly attempted FES system for paraplegic walking. There have been some problems reported with the flexor withdrawal response with prolonged repetitive stimulation. ${ }^{59}$

An implanted multichannel FES system providing standing and either swing-to or swing-through walking was developed by Brindley and associates. $^{60}$ Radio frequency linkage was used. Passive radio receivers were implanted with wire electrodes running sub-cutaneously from it to stimulate the superior and inferior gluteal nerves and the femoral nerves. An implantable 16 channel device was proposed by Thoma and his associates ${ }^{61}$ and Holle and associates. ${ }^{62}$ The stimulating ends of the electrodes were attached to the epineurium of the nerves. Four electrodes were placed equidistant radially around the nerve and the stimulating current was periodically switched among these four electrodes. This approach was called 'round about' stimulation and was used in an attempt to reduce fatigue.

Besides surface stimulation and implantable systems another method of stimulation is being used. Percutaneous insertion of intra-muscular wire electrodes made from extremely thin stainless wire has been described by Marsolais and Kobetic. ${ }^{63}$ The electrodes were made from Teflon coated stainless steel wire. The ends of the electrodes were deinsulated. Bared ends were wound in a thin coil with an anchoring hook at the tip. The implantation was carried out through a hypodermic needle. As many as 32 electrodes could be used on each side. The stimulator stimulated different muscles according to a pattern stored into it's memory. The main advantage of this method of stimulation, as perceived by Marsolais and Kobetic, were the selectivity of stimulation and the possibility 
of activation of many different muscles concurrently during a single phase of the gait cycle. The stimulation pattern was synthesized individually for each patient.

Problems concerning control of FES for restoration of gait in the spinal cord injured complete paraplegic patient are very complex. The control system can be either open loop or closed loop. Almost all of the systems presently in clinical applications use an open loop system. In an open loop control system the stimulation sequences are independent of the resulting locomotor functions. The locomotor functions may change because of many reasons but the FES system has no information about the changed situation and cannot adjust the stimulation accordingly. In the open loop control the stimulation is totally controlled by the patient.

Walking pattern based on flexion response triggering was used by Graupe and associates. ${ }^{64,65}$ The control of stimulation sequences was through the patient's electromyogram (EMG) signals. The EMG control signals were generated voluntarily by contracting the erector spinae muscles. Four different EMG signatures were discreetly generated with the help of micro-processor interface circuit and were used for four different functions.

In contrast to an open loop control system, a closed loop control system is a feedback system that utilizes an additional measure of the actual output in order to compare the actual output with the desired output response. It tends to maintain a prescribed relationship of one system variable to another by comparing functions of these variables and using the difference as a means of control.

Closed loop computer controlled walking was proposed by Petrofsky and Phillips. ${ }^{66}$ Special shoes incorporating pressure transducers were developed. Electrogoniometers were attached to the legs. Walking was divided into four phases and each phase was controlled by the inputs received by the sensors attached to the legs. Since then various other functions are being tried as feedback information to serve as a control source. These include muscle force, joint torque, pressure under feet, EMG signal and joint angle.

Extensive research in various aspects of FES is currently being carried out in a number of research centers throughout the world. The scientists involved in FES research encountered some major problems from the early period of research, namely, from the technological point of view, selectivity and effective control of stimulation, and from the physiological point of view, muscle fatigue, According to many, these problems are inter-linked. It is beyond the scope of this review to describe the work done in those areas in detail. Various stimulation strategies, ie varying pulse rate, stimulus width and amplitude, duty cycle of stimulation, incorporation of biofeedback of different parameters in order to reduce the need for prolonged stimulation have been tried. However, the technology, the extent of knowledge of mechanisms of muscle fatigue and natural control of locomotion are currently inadequate to solve these major problems. Hence the use of FES for paraplegic locomotion has still remained mainly experimental.

\section{Hybrid Orthoses}

It was quite logical to combine the two approaches, ie mechanical orthosis and FES. The resulting orthosis is called 'Hybrid' orthosis and it was proposed as early as 1973 by Tomovic and associates. ${ }^{67}$ The main advantage of a hybrid orthosis is increased safety for the patient. Usually the support, stability to joints and constraining of unwanted motion of the joints is provided by the mechanical component of the orthosis where a FES component provides or augments propulsion. Schwirlitch and Popovic ${ }^{68}$ suggested a hybrid orthosis which consisted of self fitting modular KAFO in combination with FES providing knee extension during walking. A four channel stimulator was used. The user initiated a step through flexion response triggering. Knee extensor stimulation extended the knee. Orthotic knee locking was based on friction of the joint and was activated by a micromotor. Shoe insole switches, inclinometers and joint angle sensors provided necessary information to a microprocessor controller. The control was based on a set of predetermined rules rather than a closed loop concept.

Andrews and Bajd $^{69}$ suggested two varieties of hybrid orthosis. The first consisted of a combination of a pair of simple plastic splints used to maintain the knee extension and a four channel stimulator using two channels for each leg. One channel stimulated Gastro-soleus muscles and the other provided flexor withdrawal response. Since the knee was held in extension only dorsiflexion of the foot and flexion of the hip was obtained. The gait with this method was similar to the 'four point' gait. The second system consisted of a KAFO and two channels stimulation for each leg. The Quadriceps and the common peroneal nerve were stimulated on each side. Quadriceps stimulation caused knee extension and peroneal nerve stimulation produced synergistic flexor response. The mechanical brace incorporated knee joint locks which were remotely controlled by a solenoid actuator or a Bowden cable. Andrews ${ }^{70}$ also described a short leg orthosis in combination with FES. A Floor Reaction Orthosis (FRO) was fabricated using a high density polypropylene in a usual fashion except the ankle joint was set in approximately $5^{\circ}$ plantarflexion. This has the advantage of being able to stabilize the knee joint when the ground reaction vector passes anterior to the knee joint axis. The FRO cannot stabilize the leg when the vector passes through or behind the knee joint axis. The FES control system was added to react appropriately whenever a destabilizing situation arose and to activate Quadriceps muscles. A sensor was incorporated in the calf strap of the FRO to feedback the status of the ground reaction vector. Later Andrews and associates ${ }^{71}$ suggested yet another way of using the FRO in conjunction with FES. This 
consisted of a rigid ankle foot orthosis, a multichannel stimulator with surface electrodes, body mounted sensors, a 'rule based' controller and an electrocutaneous display for supplementary feedback. The finite state controller reacted automatically to destabilizing shifts of the ground reaction vector by stimulating appropriate anti-gravity musculature to brace the leg. The system also featured a control mode to initiate and terminate flexion of the leg during forward progression. A simple mode of supplementary sensory feedback was used during the laboratory standing tests to assist the patient in maintaining a set posture.

In the cases of Reciprocating Gait Orthosis and Hip Guidance Orthosis other approaches were used. In the case of RGO the in-built mechanism to provide propulsive forces was not adequate. Solomonow and associates $^{43}$ found that ambulation with the RGO was associated with high energy cost and most patients were unable to stand up without assistance. A considerable arm strength was required for the patient to attain an upright position by pressing down on the handlebars of their walker. Most patients were unable to generate such a force. To reduce the stress over upper extremities and to reduce the energy requirements during walking an electrical stimulation system was designed to be used in conjunction with the RGO. Surface stimulation of the Rectus Femoris and Hamstrings muscles was used. The stimulation electrodes were incorporated in a plastic co-polymer cuff. The electrode cuffs were secured on the thighs with velcro straps. A four channel stimulator was worn on a belt. Finger switches were mounted on the handle bars of the walker. The stimulation was controlled by the patient himself. To stand up without assistance patient stimulated both Quadriceps and both Hamstrings simultaneously. The Quadriceps extended the knees and Hamstrings extended the hips pushing the patient in an upright position. During walking the patient simultaneously stimulated the right Quadriceps to produce right swing and left Hamstrings to produce left forward push, then again simultaneously stimulated the left Quadriceps and right Hamstrings to produce left swing and right forward push respectively. Phillips ${ }^{72}$ described a similar approach, however, in addition to the stimulation of Hamstrings, stimulation of the ipsilateral Gluteal muscles was also suggested to improve hip extension of the stance leg. Four two channel stimulators were used. The entire bulk of the Quadriceps was stimulated using three electrode configuration with two channels of one stimulator for each leg. The other two stimulators were used to stimulate the Hamstrings and Gluteal muscles on each side. The electrodes were applied directly over the skin surface instead of being incorporated in a cuff.

Nene and Major $^{73}$ studied the dynamics of the reciprocal gait of adult paraplegic patients walking using the ParaWalker. The study was undertaken because it was observed that adults did not perform as well as children using the ParaWalker. They were less confident and their ambulation endurance was often limited by pain in the hands. With any large orthosis it becomes difficult to maintain the same relative rigidity as is achieved with smaller devices. In the case of the ParaWalker it is especially true in the region of orthotic hip joints. In some adult patients deformation in this region on stance side reached such proportions that the swing leg failed to clear the ground. Pushing harder on the swing side crutch increases lateral forces and causes still more deformation on the stance side. To overcome this problem the patient is obliged to apply large forces through both crutches. They found two peaks in the vertical crutch force graphs, one in each half of the crutch contact period in adults as against one found during later period of crutch contact in a previous study of dynamics of HGO walking in one subject aged 8 years. ${ }^{74}$ An alternative method of compensating for the lack of structural rigidity by means of electrically stimulating hip abductors and extensors on stance side was tried. ${ }^{75}$ Nene and Andrews ${ }^{76}$ reported a study of six paraplegic patients walking with the ParaWalker along the surface stimulation of stance side Gluteal muscles. They reported reduction in crutch impulse in five out of six subjects with an increase in their walking speeds. They also reported the presence of concurrent contraction of anterior abdominal wall muscles causing flexion of both hips with higher amplitude stimulation in some subjects. This prevented the subjects from obtaining strong forceful contraction of the Gluteal muscles. Nene and Jennings ${ }^{77}$ reported the successful implantation of a stimulation system in a subject. The subject was an adult male, post trauma, complete paraplegic with the lesion level at T7. He had been using surface stimulation of his gluteal muscles to aid his walking with the ParaWalker but suffered unpleasant anterior abdominal wall muscles contractions with high amplitude stimulation. The experimental use of percutaneous intramuscular Platinum/Iridium wire electrodes demonstrated that more forceful contraction of gluteal muscles could be obtained without any anterior abdominal wall muscles contractions. This prompted them to use a permanent implanted system.

A research group in the Netherlands is currently working on the development of a Modular Orthosis with multichannel Surface Electrical Stimulation (MOSES) system. It is proposed that the orthotic component of the system will be of HKAFO variety with a modular construction. The trunk support will be removable to facilitate wheelchair usage and transfers to and from wheelchairs to other places in a sitting position. Also, knee joint mechanism will provide automatic unlocking of the joint during respective swing phase while remaining locked during respective stance phase. Actuation of this mechanism will be provided from the hip on the same side. This is in an attempt to reduce the energy requirements of 
locomotion and at the same time improving kinematics of locomotion. Electrical stimulation of stance side hip extensors will provide propulsion. The system is currently undergoing clinical evaluation. ${ }^{78}$

\section{Functionality}

The term 'Functionality' means many different things to different people. To the author it means general utilization of a particular system under consideration. The degree or grade of functionality may vary from system to system. Various aspects of utilization of the system will influence this grade or the level. When assessing functionality of a particular orthosis, used for ambulation by paraplegics, certain factors should be taken into consideration. They are:

(1) Energy cost of walking

(2) Independence

(3) Cosmesis

(4) System reliability-fail safe features

(5) Finances

\section{Energy requirements}

Energy cost of paraplegic walking is intrinsically high. During orthotic ambulation their lower limbs are restricted to most rudimentary mechanical function and the propulsive forces are generated by the musculature of their shoulder girdle and upper extremities. The energy requirements of paraplegic locomotion using long leg braces and crutches have been studied in the past by various researchers. The pioneering study was done by Gordon and Vanderwalde. ${ }^{11}$ Their study group consisted of 11 patients suffering from such diverse pathologies as Anterior Poliomyelitis, Cerebral Palsy Diplegia and Posttrauma Paraplegia. In their study group, ambulating in a swing-through fashion, they found that the energy requirements per minute were at least 3.5 times and often as high as 5.5 to eight times the basal requirements. The speed of ambulation was low and hence the efficiency was also very low. Other significant factors such as increasing age and inadequate bracing appeared to affect energy costs unfavorably. They concluded that paraplegic locomotion ranges from moderate to hard work and must be judiciously prescribed. Gordon ${ }^{79}$ felt that the paraplegic patient, for a full scale ambulation, must be selected on the basis of anatomical involvement, those with large trunk deficits would probably fail; those with involvement of only the trunk flexors or with cord lesions below T12 or L1 would probably succeed. However, this did not, in his opinion, preclude standing and walking short distances merely as an exercise to maintain physiological balance and carrying out self-care activities.

Clinkingbeard and associates ${ }^{80}$ studied the energy cost of paraplegic locomotion. Their purpose was not only to study the energy requirements of a larger group of post-trauma paraplegic patients but also to relate it to the level of the lesion and the duration of their training. They found that the energy requirement per unit distance (energy cost) tended to decrease while the energy requirement per unit time (energy consumption) tended to increase as the level of lesion lowered. This was closely related to the increase in the speed of locomotion as the level of lesion lowered.

A study by Huang and associates ${ }^{81}$ showed that paraplegic individuals consumed three times greater oxygen during walking than when they were at rest. A study by Chantraine and associates ${ }^{82}$ showed that when such people are allowed to ambulate at their comfortable speed the energy consumption was lower in patients who used their long leg braces regularly than in those who used braces sporadically. It was directly related to the level of spinal cord lesion. However, the gait velocity was directly related to brace use, ie the velocity was higher in patients with longer periods of regular use; and inversely related to the level of lesion, ie walking velocity was slower in patients with higher level lesions.

Cerny and associates ${ }^{83}$ found that walking was significantly more inefficient than wheelchair propulsion in paraplegic patients. This was true even for those who customarily used KAFOs for locomotion. The energy requirements for wheelchair propulsion approximated those for normal walking, ie able bodied adults walking at a comfortable self selected speed and cadence as reported by Blessey. ${ }^{84}$

Merkel and associates ${ }^{85}$ studied energy expenditure of paraplegic patients standing and walking using two types of KAFOs (Scott-Craig KAFO and Single Stopped long leg KAFO). They found no difference in energy requirements of these two orthoses during standing. The Scott-Craig KAFO appeared to be more energy efficient when used in conjunction with a walker. The energy consumption was also lower during ambulation using Scott-Craig KAFO. They concluded that the energy cost of paraplegic locomotion with either variety of orthosis is about 5 to 12.8 times that of normal locomotion as reported by Blessey. ${ }^{84}$

Miller and associates ${ }^{86}$ measured energy requirements of paraplegic locomotion during negotiating turns, stairs and ramps using the same two varieties of KAFOs. They found that the energy consumption of paraplegic locomotion during negotiations of architectural barriers was approximately the same as that for able bodied walkers. However, the energy cost was as much as 15 times more than that of normal walkers.

Merkel and associates ${ }^{87}$ reported energy requirements of paraplegic locomotion for subjects with the lesion level in high, mid and lower thoracic region ambulating using Scott-Craig KAFOs. They found that the energy cost of locomotion for paraplegic patients with a low or mid thoracic level lesion was about seven to nine times more than that for normal walking but that for paraplegic patients with a high thoracic level injury it was almost 25 times more than that of normal walking. 
All of the above mentioned studies concluded that paraplegic patients with a high or mid thoracic level lesion were probably incompatible for ambulation. However, all their study subjects ambulated using some form of KAFO, there was no trunk support provided during ambulation. Hence, a lot of energy was utilized in maintaining an upright posture. Nene and Patrick ${ }^{88}$ studied the energy cost of locomotion for thoracic level paraplegic people using the ParaWalker. As mentioned previously, the ParaWalker gives adequate support to the trunk and offers more stability than KAFOs. They found that the energy consumption with the ParaWalker was about 3.45 times the resting level of the subjects. They found no relationship between the energy consumption and level of lesion and walking speeds. The energy cost was 4.9 times more than that of normal walking; this was in contrast to the findings for paraplegics with thoracic level lesion reported in the previous studies. They deduced that the efficiency of the ParaWalker lies in the intrinsic stability provided by the orthosis. Surface electrical stimulation of stance side gluteal muscles helped to reduce the energy cost of locomotion by approximately $6.5 \%$ to $8 \%$ in the study group of five subjects. ${ }^{89}$ They inferred that the stimulation of large muscles like the Gluteus Maximus and Gluteus Medius increases the active muscle mass and thereby over time would increase the patients' maximal aerobic capacity and the anaerobic threshold.

In a study comparing energy requirements of ambulation using the RGO alone and hybrid RGO, Hirokawa and associates ${ }^{90}$ found approximately $16 \%$ reduction in the energy cost throughout the full range of walking speeds when RGO was combined with electrical stimulation of the thigh muscles. They concluded that at slow speeds the energy cost of ambulation using RGO was less than that using KAFOs. However, the absolute figures of the energy cost or consumption using RGO were not quoted. Merritt and associates ${ }^{91}$ studied a group of five paraplegic patients who had both types of orthosis, ie the RGO \& Scott-Craig KAFOs prescribed to them. They studied the energy consumptions and energy costs of swing-through and reciprocal gaits using both orthoses at varied velocities. Obviously higher velocities were attained using a swing-through pattern with both orthosis than using reciprocal pattern. Regardless of the velocity the energy cost of reciprocal gait using the RGO was lower than that using KAFOs. When the patients ambulated with a swing-through pattern the energy cost was lower with KAFOs than with the RGO. The energy consumption was lower with the RGO during a reciprocal gait but it was similar for both orthoses when the patients walked with a swing-through pattern.

Winchester and associates ${ }^{47}$ examined the energy cost of ambulation using a standard RGO and using a modified RGO, ie Isocentric RGO. They found that with the standard RGO patients' oxygen uptake was
$14.2 \mathrm{ml} \mathrm{kg}^{-1} \min ^{-1}$ (mean) and the mean velocity was $12.7 \mathrm{~m} \mathrm{~min}^{-1}$; with the isocentric RGO the oxygen uptake was $13.0 \mathrm{ml} \mathrm{kg} \mathrm{min}^{-1}$ (mean) and the mean velocity was $13.5 \mathrm{~m} \mathrm{~min}^{-1}$ (although the $P$-values were given it was noted that the differences were statistically not significant). If one treats these findings in a way described by Nene and Patrick ${ }^{89}$ one finds the energy consumption to be $4.8 \mathrm{~J} \mathrm{~kg}^{-1} \mathrm{~s}^{-1}$ and the energy cost to be approximately $22.6 \mathrm{~J} \mathrm{~kg}^{-1} \mathrm{~m}^{-1}$ with the standard RGO; with the isocentric RGO the energy consumption was $4.4 \mathrm{~J} \mathrm{~kg}^{-1} \mathrm{~s}^{-1}$ and the energy cost was approximately $19.4 \mathrm{~J} \mathrm{~kg}^{-1} \mathrm{~m}^{-1}$. These values appear to be higher than those reported for the ParaWalker ambulation. ${ }^{88}$ However, Whittle ${ }^{44}$ did not find any significant difference between the energy requirements of ambulation using RGO and ParaWalker as estimated by the oxygen uptake and pulse rate.

Only one study so far on the energy requirements of FES walking alone has been reported in the literature. Marsolais and associates ${ }^{92}$ reported energy requirements of walking using FES alone and compared those to using KAFOs in three patients. During FES walking energy consumption was about $59-75 \%$ of maximal aerobic power of the patients. There was no increase in energy consumption when the walking speed was increased. Energy cost equalled that of KAFOs. At speeds approaching $0.4 \mathrm{~m} \mathrm{~s}^{-1}$ FES walking energy consumption was similar to that of KAFOs. They inferred that at speeds between $0.4 \mathrm{~m} \mathrm{~s}^{-1}$ and $0.6 \mathrm{~m} \mathrm{~s}^{-1}$ FES walking is a viable alternative to ambulation using KAFOs. They hoped that major energy cost reduction would be possible in the future.

Energy expenditure has traditionally been determined through the measurement of oxygen consumption. However, this requires for the subject to wear a face mask or a nose clip and either breathe into a douglas bag or a portable oxygen consumption meter. In clinical situations involving paraplegic patients this method proves to be impractical and may also necessitate the availability of a respiratory laboratory. In able bodied subjects heart rate and oxygen uptake have a linear relation up to sub maximal workloads. This enables researchers to monitor the energy costs of a variety of activities by monitoring heart rate alone. There has been a doubt expressed regarding suitability of the heart rate monitoring in paraplegics with the lesion level above T6 as many workers have suggested that the sympathetic contribution to the cardiac plexus arises between $\mathrm{T} 1$ and $\mathrm{T} 6$. Bar-On and Nene ${ }^{93}$ carried out a study to find relationship between heart rate and oxygen uptake in thoracic level paraplegic patients. They studied 44 such individuals with lesion levels between T3 and T10. All were put through an incremental arm cranking exercise while monitoring their heart rate and oxygen uptake. An almost linear relation was found between the two parameters in all subjects. They suggested that either the sympathetic contribution comes from above 
spinal level $\mathrm{T} 3$ or the cardiac response to an increased demand in physical exercise is controlled by some other mechanism.

In the past it has been shown that it was possible to establish walking performance of patients by monitoring speed and heart rate. ${ }^{94,95}$ MacGregor ${ }^{96,97}$ described a method of combining these two parameters to produce a single index called the Physiological Cost Index (PCI). Nene and Jennings ${ }^{98}$ felt that the method of measurement of heart rate can also be used for monitoring performance of paraplegic walking. They measured the PCI of paraplegic locomotion using the ORLAU ParaWalker. In a study group of 16 subjects mean PCI was 3.11 beats per meter $\left(\mathrm{b} \mathrm{m}^{-1}\right)$. It ranged from $1.47 \mathrm{~b} \mathrm{~m}^{-1}$ to $4.76 \mathrm{~b} \mathrm{~m}^{-1}$. Bowker and associates $^{99}$ reported a mean PCI value of $5.04 \mathrm{~b} \mathrm{~m}^{-1}$ for a group of $28 \mathrm{RGO}$ users. Their subject group consisted of patients with paraplegia due to varied pathology.

Nene and Jennings ${ }^{98}$ were of the opinion that this simple method of calculation of energy expenditure will be very appropriate as an indicator of energy expenditure for an individual using different orthosis or trying out modifications to the same orthosis. Winchester and associates ${ }^{47}$ concurred with the opinion. They felt that the PCI can be used as a tool in the assessment of gait efficiency in spinal cord injured subjects. Combining a physiological measurement like heart rate with a functional measurement such as velocity may make the PCI a more sensitive measure for detecting small but significant differences in energy expenditure. They found a mean PCI of $3.6 \mathrm{~b} \mathrm{~m}^{-1}$ (SD $0.66 \mathrm{~b} \mathrm{~m}^{-1}$ ) in their four subjects when walked using the standard RGO and $2.6 \mathrm{~b} \mathrm{~m}^{-1}$ (SD $\left.0.47 \mathrm{~b} \mathrm{~m}^{-1}\right)$ using the Isocentric RGO $(P=0.04)$. Isakov and associates ${ }^{100}$ reported a dramatic reduction of PCI in their subject when ambulating with hybrid RGO compared to that when walked with the RGO alone. With the RGO alone it was $2.55 \mathrm{~b} \mathrm{~m}^{-1}$ but it reduced to $1.54 \mathrm{~b} \mathrm{~m}^{-1}$ when she walked using surface FES of Quadriceps, Hamstrings and Gluteus maximus in conjunction with the RGO.

\section{Independence and walking ability}

A paraplegic person should be able to use the orthosis completely independently. This includes doffing and donning; transfers, ie, standing up, walking and sitting down again. The patient must also be able to negotiate commonly encountered architectural barriers such as gentle slopes, curbs, steps etc. Transfers in and out of wheelchairs, cars and other means of transport are also essential for everyday life of a paraplegic. All presently available KAFOs can be donned and doffed by the patients independently. Patients with severe spasticity and contractures have some difficulty in doffing and donning the ParaWalker and the RGO. ${ }^{43,101}$ The RGO had knee joints with automatic knee locks which caused difficulty for some patients. These have been modified and the newer generation of RGO has ratchet knee joints. ${ }^{43}$ The HGO users need to extend and lock their knees before they are able to stand up. A special assistive device can be made for individuals who have difficulty with locking their knees.

McAdam and Natvig ${ }^{102}$ reviewed 61 paraplegic patients using KAFOs. Sixteen with the lesion level between $\mathrm{T} 1$ and $\mathrm{T} 8$ were able to climb 20 or more steps, while 15 were unable to climb 20 steps. Twenty with lesion levels between T9 and L3 were able to climb 20 or more steps, while only 10 were unable to climb 20 steps. In their opinion paraplegic patients who could ambulate well using crutches and in particular could climb stairs had a greater chance of successful vocational rehabilitation. Patients using the ParaWalker can manage a small step or curb about $15 \mathrm{~cm}$ high. They are unable to manage a step higher than that. ${ }^{101}$ They also can manage to negotiate gentle slopes. With the orthotic hip modification the RGO users also can manage gentle slopes and small steps. ${ }^{43}$

Since hip adduction/abduction is unconstrained in KAFO users they do not encounter any problems getting in and out of a car. Amongst ParaWalker users, out of 46 who answered the questionnaire, 20 were able to get in the car as a passenger and 26 were unable. Fourteen were able to drive the car wearing the orthosis while 32 were unable to drive. ${ }^{101}$

Stand alone FES systems have yet to graduate from the laboratory scene. Their efficacy in routine clinical use is not yet known. There have been some problems reported regarding easy access to the electrode sites by hybrid ParaWalker users. ${ }^{76}$

The other major factor which can hamper independence is the ability to perform toiletting functions while using the orthosis. Use of either the ParaWalker or RGO certainly causes major problems in this area. Use of KAFOs, due to hips being unconstrained, does not cause serious inconveniences.

A normal functional ambulator is considered to be a person who can walk about 75 meters in one minute and can cover a distance of about 250 meters without any problems. Very few paraplegic individuals ambulating with orthosis can accomplish these criteria and hence functional ambulation for them can be redefined to include the use of orthosis for most daily activities and the use of a wheelchair for long distance travel only. ${ }^{103}$ Even then very few paraplegic patients qualify as functional ambulators according to the revised definition. Natvig and $\mathrm{McAdam}^{25}$ reported findings of a 10 year follow up study with 42 complete paraplegics. Seventy-one per cent of their patients were able to walk about 100 meters indoors after completion of their physical training. In a review of historical studies concerning use of KAFOs for paraplegic locomotion, Mikelberg and Reid ${ }^{104}$ summarized that less than $50 \%$ of the patients from these studies continued to use them functionally. The others used them mainly for standing and limited walking. In the survey of ParaWalker users it was found that out of a total of 50 patients 32 used the orthosis on a regular basis. Amongst those, 30 walked outdoors using the orthosis. Twelve were unable to walk farther 
than 100 meters but the rest (18 patients) could walk well beyond 100 meters. Few paraplegic individuals used their orthosis for some activities other than therapeutic or leisure exercise. ${ }^{101}$ It is now accepted that the ParaWalker is primarily used as a therapeutic and social device and has extremely limited functional value.

\section{Cosmesis}

Cosmesis has considerable subjective overtones attached to it and hence it is very difficult to assess the importance of cosmesis of a given orthosis objectively. Nevertheless there are some important factors which need to be taken into consideration concerning overall cosmesis of the orthosis. They are:

(a) Appearance of the orthosis

(b) Whether it can be worn underneath the clothes or not

(c) The nature of walking aids used in conjunction with the orthosis; and

(d) Style of walking

Hardly any study concerning KAFOs has looked into this aspect of functionality. Amongst the two commonly used HKAFOs patients preferred to use the RGO, mainly for its better cosmesis. It could be worn underneath the clothes and shoes. ${ }^{105}$

\section{Fail safe features}

Any walking system used for paraplegic walking must have a very high level of reliability, but at the same time in case of any unforeseeable failure the user must not come to any physical harm. All mechanical systems currently in use are fairly robust and fail safe. Stand alone FES systems fail to provide any mechanical safety in the case of failure of electronic components during walking. With percutaneously implanted electrodes the rate of electrode failure is high thereby necessitating re-implantation of the electrodes. Additionally, the electrode insertion sites acting as portals for entry for infecting organisms remain a theoretical risk.

\section{Financial aspects}

Main elements of the cost of an orthotic system are:

(a) the orthosis

(b) walking aids

(c) surgery or any other procedures required

(d) fitting and training

(e) maintenance

No published data is available concerning breakdown of costs involved in the supply of KAFOs. In a comparative study of the ParaWalker and the RGO these costs have been studied. The study concluded that the only statistically significant difference in cost between the two orthosis was in the actual fabrication costs. Other costs such as training and out of pocket expenses for the patient were similar between the orthoses. ${ }^{106}$ The costs of FES systems for routine clinical supply are yet to be ascertained. In the centers where the research work is being carried out the costs are extremely high.

\section{Conclusion}

Looking at the usage of various orthotic systems proposed for paraplegic locomotion, functionality of the system appears to be vital in the clinical success of the system. Patients will use the system only if it is 'user friendly', appropriate and it allows them to perform other functions when wearing the system. Regarding physiological benefits, it will be highly desirable if a long term study can be designed and carried out to obtain objective findings concerning the physiological benefits of walking in paraplegics and bury the empirical myth of subjective feelings held by the physicians regarding these benefits. Although there has been a lot of discussion regarding energy requirements of paraplegic locomotion using various systems; ambulation for paraplegic individuals has remained mainly therapeutic, ie for exercise purposes only. The system, in general, is worn for a few hours at a time and on a few occasions every week. Under such circumstances the debate about energy requirements of various orthosis and the superiority of one system over the other becomes less important. Generally, the energy requirements for paraplegic walking are high and the cosmesis is poor with almost all of the orthotic systems. Under these circumstances, paraplegic patients who wish to ambulate should be given clear cut information concerning orthotic ambulation and should not be given a glamorized impression of paraplegic locomotion, which popular media tend to portray. Walking is not the panacea for all of their problems. At the same time, after the difficulties and limitations of orthotic walking have been explained, if they still wish to pursue walking then the provision of an appropriate orthotic system should not be denied to them.

\section{References}

1 Elsberg CA. The Edwin Smith surgical papyrus and the diagnosis and treatment of injuries to the skull and spine 5000 years ago. Ann Med Hist 1931; 3: 271.

2 Poer DH. Newer concepts in the treatment of the paralysed patient due to wartime injuries of the spinal cord. Ann Surg 1946; 123: 510 .

3 Euel A. Restorative management of paraplegic patient: Philosophy and concept of bracing. New York State J Med 1968; pp. 2037-2040.

4 Hinman F. The treatment of paralytic bladder in cases of spinal cord injury. Surgery 1938; 4: 649.

5 Coonrad RW, Whiteside ES. Traumatic paraplegia: A classification and fifteen year follow up. Southern Med Journal 1954; 47: 350-356.

6 Hastings JEF. A study of the paraplegic patient. Workmen's Compensation Board, Ontario Canada. 1959.

7 Zankel HT, Sutton BB, Burney TT. A paraplegic program under Physical Medicine and Rehabilitation: One year's experience. Arch Phys Med 1955; 36: 249-255. 
8 Munro D. Two year end results in total rehabilitation of veterans with spinal cord and cauda equina injuries. New Eng $J$ Med 1950; 242: 1- 16 .

9 Munro D. Rehabilitation of patients totally paralysed below waist, with special reference to making them ambulatory and capable of earning their own living. New Eng J Med 1954; 250: $4-14$.

10 Long C, Lawton EB. Functional significance of spinal cord lesion level. Arch Phys Med 1955; 36: $249-255$.

11 Gordon EE, Vanderwalde $\mathrm{H}$. Energy requirements in paraplegic ambulation. Arch Phys Med 1956; 36: 276-285.

12 Covalt DA, Cooper IS, Hoen TI, Rusk HA. Early management of patients with spinal cord injury. JAMA 1953; 151: 89-94.

13 Abramson AS. Principles of bracing in rehabilitation of paraplegia. Bull Hosp Joint Dis 1949; 10: 175- 182.

14 Hussey R W, Stauffer ES. Spinal cord injury: Requirements for ambulation. Arch Phys Med Rehabil 1973; 54: $544-547$.

15 Rosman N, Spira E. Paraplegic use of walking braces: A survey. Arch Phys Med Rehabil 1974; 55: 310-314.

16 Stauffer ES, Hoffer MM, Nickel VL. Ambulation in thoracic paraplegia. J Bone \& Joint Surg 1978; 60A: $823-824$.

17 Rose GK. The principles and practice of Hip Guidance Articulations. Prosth \& Orth Intnl 1979; 3: 37 43.

18 Douglas R, Larson PF, D'Ambrosia R, McCall RE. The LSU Reciprocating Gait Orthosis. Orthopedics 1983; 6: $834-839$.

19 Dinken H. Physical treatment and rehabilitation of paraplegic patients. JAMA 1951; 146: 232-234.

20 Rusk HA. Rehabilitation Medicine: A Textbook on Physical Medicine and Rehabilitation, 2nd Edition, Mosby Co, St. Louis. 1964.

21 Rossier AB. Rehabilitation of the spinal cord injury patient. Acta Clinica No 3 1964; North American Service, New York.

22 Jackson RR. Do you recommend long leg braces for patients with paraplegia? If so, what type of bracing do you prefer. Phys Ther 1971; 51: 823.

23 Hahn HR. Lower extremity bracing in paraplegics with usage follow up. Paraplegia 1974; 8: $147-153$.

24 Silber M et al. Pneumatic orthosis: Pilot study. Arch Phys Med Rehab 1975; 56: $27-32$.

25 Natvig H, McAdam R. Ambulation without wheelchairs for paraplegics with complete lesions. Paraplegia 1978; 16: $142-$ 146

26 Guttman L. Spinal Cord Injuries: Comprehensive Management and Research. Blackwell Scientific Publications, Oxford. 1973.

27 Rosenstein BD, Greene WB, Herrington R T, Blum AS. Bone density in myelomeningocele: The effect of ambulatory status and other factors. Dev Med Child Neurol 1987; 29: 486-494.

28 Mazur JM, Shurtleff D, Menelaus M, Colliver J. Orthopedic management of high level spina bifida. $J$ Bone \& Joint Surg 1989; 71A: $56-61$.

29 Messenger N, Rithalia SVS, Bowker P, Ogilvie C. Effects of ambulation on the blood flow in paralysed limbs. J Biomed Eng 1989; 11: $249-252$.

30 Ogilvie C, Bowker P, Rowley DI. The Physiological benefits of paraplegic orthotically aided walking. Paraplegia 1993; 31: $111-115$.

31 Stallard JS, Major RE, Patrick JH. A review of fundamental design problems of providing ambulation for paraplegic patients. Paraplegia 1989; 27: 70-75.

32 Rose GK. Orthosis for the severely handicapped-Rational or Empirical choice. Physiotherapy 1980; 66: 76-81.

33 Stallard JS, Rose GK. The components of orthotic ambulation. The Journal of the British Institute of Surgical Technologists 1981; 1: 44-52.

34 Motlock WM, Elliott J. Fitting and training children with Swivel Walkers. Artificial Limbs 1966; pp. $27-38$.

35 Edbrooke H. The Royal Salop Infirmary 'clicking splint'. Physiotherapy 1970; 56: 148.

36 Rose GK, Henshaw JT. A Swivel Walker for paraplegics: Medical and Technical considerations. Biomed Eng 1972; 7: $420-425$.
37 Rose GK, Henshaw JT. Swivel Walkers for paraplegics: Considerations and problems in their design and application. Bull Prosth Res 1973; 10-20: 62-74.

38 Farmer IR, Poiner R, Rose GK, Patrick JH. The adult Swivel Walker-Ambulation for paraplegic and tetraplegic patients. Paraplegia 1982; 20: $248-254$.

39 Stallard JS, et al. Engineering design considerations of the ORLAU Swivel Walker. Engineering in Medicine 1986; 15: 3 8.

40 Butler PB, Major RE, Patrick JH. The technique of reciprocal walking using the Hip Guidance Orthosis with crutches. Prosth \& Orthot Intnl 1984; 8: $33-38$

41 Andrews BJ. A prototype modular hybrid FES or thotic system for paraplegics. Proc Int Symp External Control of Human Extremities 1990; Dubrovnik, Yugoslavia, pp. 187-196.

42 Scrutton DR. A reciprocating brace with polyplanar hip hinges used on spina bifida children. Physiotherapy 1971; 57: 61 -66.

43 Solomonow $\mathrm{M}$, et al. The RGO Generation II: Muscle stimulation powered orthosis as a practical walking system for thoracic paraplegics. Orthopedics 1989; 12: 1309-1315.

44 Whittle MW. Biochemical Assessment. In 'A comparative evaluation of the Hip Guidance Orthosis( $\mathrm{HGO}$ ) and the Reciprocating Gait Orthosis (RGO). HEI No 192, NHS Procurement Directorate, Dept of Health, HM Govt, UK. July 1989.

45 Jefferson RJ, Whittle MW. Performance of three walking orthosis for the paralysed: a case study using gait analysis. Prosthet Orthot Int 1990; 14: $103-110$.

46 Motlock WM. Principles of orthotic management for child and adult paraplegia and clinical experience with the Isocentric RGO. Proc 7th World Congress of the International Society for Prosthetics and Orthotics 1992; Chicago, p 28.

47 Winchester PK, et al. A comparison of paraplegic gait performance using two types of reciprocating gait orthoses. Prosthet Orthot Int 1993; 17: $101-106$.

48 Lehmann JF, et al. Biomechanical evaluation of braces for paraplegics. Arch Phys Med Rehab 1969; 50: 179-188.

49 Lehmann JF, Warren CG. Restraining forces in various designs of Knee-Ankle Orthosis: Their placement and effect on anatomical knee joint. Arch Phys Med Rehab 1976; 57: $430-437$.

50 Lehmann JF et al. Craig-Scott Orthosis: A biomechanical and functional evaluation. Arch Phys Med Rehab 1976; 57: $438-$ 442.

51 Scott BA. Engineering principles and fabrication techniques for the Scott-Craig long leg brace for paraplegics. Orthot Prosthet 1971; 25: 14 - 19

52 Lyles M, Munday J. Report on the evaluation of the VanniniRizzoli stabilizing limb orthosis. J Rehab Res \& Dev 1992; 29: $77-104$.

53 Liberson WT, Holmquest HJ, Scott D, Dow A. Functional electrotherapy: stimulation of the peroneal nerve synchronized with the swing phase of the gait in hemiplegic patients. Arch Phys Med Rehab 1961; 42: 101 - 105.

54 Kralj A, Grobelink S, Vodovnik L. Electrical stimulation of paraplegic patients - feasibility study. Proc Int Symp External Control of Human Extremities 1973; Dubrovnik, Yugoslavia, p. 561.

55 Kralj A, Grobelink S. Functional electrical stimulation - a new hope for paraplegic patients. Bull Prosth Res 1973; 20: 75.

56 Kralj A, Bajd T, Turk R. Electrical stimulation providing functional use of paraplegic patient muscles. Med Prog Technol 1980; 7: 3-9.

57 Bajd T et al. The use of a four channel electrical stimulator as an ambulatory aid for paraplegic patients. Physical Therapy 1983; 63: $1116-1120$.

$58 \mathrm{Kralj} \mathrm{A}$, et al. Gait restoration in paraplegic patients: a feasibility demonstration using multichannel surface electrode FES. J Rehab Res \& Dev 1983; 20: 3-20. 
59 Andrews BJ, Baxendale RH, Granat MH, Nicol DJ. Flexion withdrawal reflexes in spinal injured man. J Physiology 1990; 429: $50 \mathrm{P}$.

60 Brindley GS, Polkey CE, Rushton DN. Electrical splinting of the knee in paraplegia. Paraplegia 1979; 16: 428-435.

61 Thoma H, Holle J, Moritz E, Stöhr H. Walking after paraplegia - A principle concept. Proc Int Symp on External Control of Human Extremities 1978; Dubrovnik, Yugoslavia, p. 71.

62 Holle $\mathrm{J}$ et al. Functional electrostimulation of paraplegics experimental investigation and first clinical experience with an implantable stimulation device. Orthopedics 1984; 7: 1145.

63 Marsolais EB, Kobetic R. Implantation techniques and experience with percutaneous intramuscular electrodes in the lower extremities. J Rehab Res \& Dev 1986; 23: 1 -8.

64 Graupe D, Kohn K H, Kralj A, Basseas S. Patient controlled electrical stimulation via EMG signature discrimination for providing certain paraplegics with primitive walking functions. J Biomed Eng 1983; 5: 220.

65 Graupe D, Kohn KH, Basseas S, Naccarato E. Electromyographic control of functional electrical stimulation in selected patients. Orthopedics 1984; 7: 1134.

66 Petrofsky JS, Phillips CA. Closed loop control of movement of skeletal muscle. CRC Critical Rev in Biomed Eng 1983; 13: 35 96.

67 Tomovic R, Vukobratovic M, Vodovnik L. Hybrid actuators for orthotic systems - Hybrid assistive system. Proc Int Symp External Control of Human Extremities 1973; Dubrovnik, Yugoslavia, p. 73.

68 Schwirlitch L, Popovic D. Hybrid orthosis for deficient locomotion. Proc Int Symp External Control of Human Extremities 1984; Dubrovnik, Yugoslavia, pp. 23-32.

69 Andrews BJ, Bajd T. Hybrid orthosis for paraplegics. Proc Int Symp External Control of Human Extremities 1984; Dubrovnik, Yugoslavia, (Suppl); 55-57.

70 Andrews BJ. A short leg hybrid FES orthosis for assisting locomotion in SCI subjects. Proc 2nd Vienna Int Workshop on Functional Electrostimulation 1986; Vienna, pp. 311 . 315.

71 Andrews BJ et al. Hybrid FES orthosis incorporating closed loop control and sensory feedback. J Biomed Eng 1988; 10: $189-195$.

72 Phillips CA. Electrical muscle stimulation in combination with a reciprocating gait orthosis for ambulation by paraplegics. $J$ Biomed Eng 1989; 11: 338 - 344

73 Nene AV, Major RE. Dynamics of reciprocal gait of adult paraplegics using the ParaWalker (Hip Guidance Orthosis). Prosthetics \& Orthotics International 1987; 11: $124-127$.

74 Major RE, Stallard JS, Rose GK. The dynamics of walking using the Hip Guidance Orthosis (hgo) with crutches. Prosthet Orthot Int 1981; 5: 19-22

75 Patrick JH, McClelland MR. Low energy cost reciprocal walking for the adult paraplegic. Paraplegia 1985; 23: 113-117.

76 Nene AV, Andrews BJ. An assessment of ParaWalker hybrid orthosis. Proc 2nd Vienna Int Workshop on Functional Electrostimulation 1986; Vienna, pp. 79-82.

77 Nene AV, Jennings SJ. Hybrid paraplegic locomotion with the ParaWalker using intramuscular stimulation: A single subject study. Paraplegia 1989; 27: $125-132$.

78 Hermens HJ et al. Advances in hybrid systems. A paper presented at the 10th Congress of the International Society of Electrophysiology and Kinesiology, Charleston, USA, June 1994.

79 Gordon EE. Physiological approach to ambulation in paraplegia. JAMA 1956; 161: 686-688.

80 Clinkingbeard JR, Gersten JW, Hoehn D. Energy cost of ambulation in the traumatic paraplegic. Am J Phys Med 1964; 43: $157-165$.

81 Huang CT, Kuhlemeier KV, Moore NB, Fine PR. Energy cost of ambulation in paraplegic patients using Craig-Scott braces. Arch Phys Med Rehabil 1979; 60: 595-600.

82 Chantraine A, Crielaard JM, Onkelinx A, Pirnay F. Energy expenditure of ambulation in paraplegics: Effects of long term use of bracing. Paraplegia 1984; 22: $173-181$.
83 Cerny K, Waters R, Hislop H, Perry J. Walking and wheelchair energetics in persons with paraplegia. Physical Therapy 1980; 60: $1133-1139$.

84 Blessey R. Energy cost of normal walking. Orthop Clin North Am 1978; 9: $356-358$

85 Merkel KD, Miller NE, Westbrook PR, Merritt JL. Energy expenditure of paraplegic patients standing and walking with two Knee-Ankle-Foot orthosis. Arch Phys Med Rehabil 1984; 65: $121-124$.

86 Miller NE, Merritt JL, Merkel KD, Westbrook PR. Paraplegic energy expenditure during negotiation of architectural barriers. Arch Phys Med Rehabil 1984; 65: 778-779.

87 Merkel KD, Miller NE, 'Merritt JL. Energy expenditure in patients with low, mid or high thoracic paraplegia using Scott-Craig Knee-Ankle-Foot orthosis. Mayo Clin Proc 1985; 60: $165-168$.

88 Nene AV, Patrick JH. Energy cost of paraplegic locomotion with the ORLAU ParaWalker. Paraplegia 1989; 27: 5-18.

89 Nene AV, Patrick JH. Energy cost of paraplegic locomotion using the ParaWalker-Electrical stimulation 'Hybrid' orthosis. Arch Phys Med Rehabil 1990; 71: $116-120$.

90 Hirokawa $\mathrm{S}$ et al. Energy consumption in paraplegic ambulation using the reciprocating gait orthosis and electric stimulation of the thigh muscles. Arch Phys Med Rehabil 1990; 71: $687-694$.

91 Merritt JL, Miller NE, Hanson TJ. Preliminary studies of energy expenditures in paraplegics using swing through and reciprocating gait patterns. Arch Phys Med Rehabil 1983; 64: 510.

92 Marsolais EB, Edwards BG. Energy costs of walking and standing with functional neuromuscular stimulation and long leg braces. Arch Phys Med Rehabil 1988; 69: 243-249.

93 Bar-On Z, Nene AV. Relationship between heart rate and oxygen consumption in thoracic level paraplegics. Paraplegia 1990; 28: $87-95$.

94 Stallard J, Rose GK, Tait JH, Davies JB. Assessment of orthosis by means of speed and heart rate. $J$ Med Eng Technol 1978; 2: $22-24$

95 Stallard J, Rose GK. Clinical decision making with the aid of a mbulatory monitoring of heart rate. Prosth \& Orth Intnl 1980; 4: $91-96$.

96 MacGregor J. The objective measurement of physical performance with Long term Ambulatory Physiological Surveillance Equipment (LAPSE). In: Stott FD, Raftery EB, Goulding L, eds. Proceedings of 3rd International Symposium on Ambulatory Monitoring 1979; Academic Press, London, pp. $29-39$

97 MacGregor J. The evaluation of patient performance using long term ambulatory monitoring technique in the domiciliary environment. Physiotherapy 1981; 67: 30-33.

98 Nene AV, Jennings SJ. Physiological Cost Index of paraplegic locomotion using the ORLAU ParaWalker. Paraplegia 1992; 30: $246-252$.

99 Bowker P, Messenger N, Ogilvie C, Rowley DI. Energetics of paraplegic walking. J Biomed Eng 1992; 14: 344-350.

100 Isakov E, Douglas R, Berns P. Ambulation using the reciprocating gait orthosis and functional electrical stimulation. Paraplegia 1992; 30: $239-245$.

101 Moore P, Stallard JS. A clinical review of adult paraplegic patients with complete lesions using the ORLAU ParaWalker. Paraplegia 1991; 29: 191 - 196.

102 McAdam R, Natvig H. Stair climbing and ability to work for paraplegics with complete lesions - A sixteen year follow up. Paraplegia 1980; 18: $197-203$.

103 Merritt JL. Knee-Ankle-Foot orthotics. Phys Med Rehabil: state of the art reviews 1987; 1: $67-82$.

104 Mikelberg R, Reid S. Spinal cord lesions and lower extremity bracing: An overview and follow up study. Paraplegia 1981; 19: $379-385$. 
105 Cochrane GM. Clinical and ergonomic aspects. In 'A comparative evaluation of the Hip Guidance Orthosis(HGO) and the Reciprocating Gait Orthosis(RGO)'. HEI No 192, NHS Procurement Directorate, Dept of Health, HM Govt, UK. July 1989.
106 Fen PT Comparison of costs. In 'A comparative evaluation of the Hip Guidance Orthosis(HGO) and the Reciprocating Gait Orthosis(RGO)'. HEI No 192, NHS Procurement Directorate, Dept of Health, HM Govt, UK. July 1989. 